\title{
LONG-TERM STRENGTH AND DEFORMATIONAL ANALYSIS OF REINFORCED CONCRETE COLUMNS
}

\author{
Valery Simbirkin ${ }^{1}$, Robertas Balevičius ${ }^{2}$ \\ ${ }^{1}$ Belarussian Research Institute for Construction (BelNIIS), Staroborisovsky trakt 15, 220114 Minsk, Belarus. \\ E-mail: simbirkin@hotmail.com \\ ${ }^{2}$ Laboratory of Numerical Modelling of Vilnius Gediminas Technical University, Sauletekio al. 11, LT-10223 \\ Vilnius-40,_Lithuania.E-mail: Robertas.Balevicius@st.vtu.lt
}

Received 16 Dec 2003; accepted 9 Feb 2004

\begin{abstract}
The paper presents a method of non-linear analysis of load-carrying capacity and deformations of reinforced concrete columns subjected to long-term loads. Physical relationships expressing non-linear relations between internal forces and stresses, strains and stiffness are derived on the basis of the fracture and creep theories for concrete and using non-linear stress-strain diagrams modified for time effects. Second-order geometrical effects are taken into account by solving a second-order differential equation for elements subjected to compression and bending. A number of numerical and test results are presented. The technique proposed is verified by comparison of analysis results with extensive experimental data.
\end{abstract}

Keywords: reinforced concrete columns, physical and geometrical non-linearity, long-term loading, strength, displacements.

\section{Introduction}

In current practice of reinforced concrete structural design, the limiting states of strength are investigated using ultimate equilibrium schemes but distribution of internal forces and displacements is normally established using simplified linear models based on assumptions of small strains and the Hook's law. Such contradiction of the analysis models is especially evident for rather slender structures where even small strains can cause large displacements. Reinforced concrete columns are an example of such structures, especially if they are made of high-strength concretes and have small cross-sections, large load eccentricities and minimum amounts of reinforcing steel. As a result, this may lead to instability problems, which can overcome advantages of the highstrength materials.

In columns of real-world buildings, a long-term part of the load, ie the load sustained for a greater part of the building service life, is rather high (about 60-80\%). Therefore, long-term non-linear effects cannot be neglected in design [1-3]. According to building codes, for example $[4,5]$, the strength of columns is usually evaluated using the following steps:

a) Estimate the end-restraint conditions and calculate the effective length of the column;

b) Where second-order effects cannot be neglected, convert the given slender column into an equivalent short column subjected to appropriately magnified factored bending moments. Take capacity of the slender column be equal to the cross-sectional strength of this equivalent short column.

These code approaches are usually presented in a closed-form analytical form and simple in use but they are empirical. They operate using integral reinforced concrete stiffness properties but not the material constitutive laws for real loading history and, therefore, cannot predict the real buckling mode.

Several studies [6-8] on the analysis of slender reinforced concrete columns have adopted analytical methods, which assume the deflection curve of the column as a cosine, or sine wave and then solve the governing differential equations. As the load exceeds the elastic limit, the deflection shape of the column gradually differs from the approximate deflection curves. Moreover, these approaches are almost impossible when the column is a part of a complex structure.

Numerical analysis procedures can be simplified when analytical moment-curvature relationships are known in advance. Sheikh [9] has performed an analytical overview of such methods for reinforced concrete columns. Manzelli et al [10] presented an equivalent linear approximation of the non-linear moment-curvature relationships for cross-sections of columns under shortterm loading. Biaxial bending moment-axial force-cur- 
vature diagrams taking into account long-term effects were presented by Rodriguez-Gutierrez et al [11] for reinforced, partially and fully prestressed concrete sections. Hsu [12] proposed a classification of analytical models used for line reinforced concrete members.

If the concrete compressive stress exceeds a half of the compressive strength, the stress-strain relation becomes strongly non-linear. This is also true in a case of sustained loading of a reinforced concrete column, where creep effect is present. Modelling the non-linear material behaviour is substantially important in creep stability analysis when the bifurcation point on the deformation path of a structure must be detected.

There is an extensive theoretical research [13] into reinforced concrete creep stability, but a few works deal with non-linear creep effects, for example [14-16]. The problem lies in a lack of comprehensive analytical representation of non-linear creep effects in literature.

One of the ways to predict a non-linear response of concrete to long-term compression is based on using rheological models (eg, Mazzotti et al [17]), Barpi et al [18]). However, if conventional step-by-step integration methods are used for integration of the Maxwell's chain equations, such as the Euler's method, the Runge-Kutta methods or predictor-corrector methods, a problem of reliable determination of the time increment can be present. The time increment should not exceed the shortest relaxation time in order to avoid numerical instability problems. These approaches enable to take into account variable physical and mechanical properties of concrete in the fracture process, but here there is a problem associated with determination of a whole range of dissipative mechanisms in a single rheological element and, therefore, these approaches are suitable only for a particular concrete.

An advanced up-to-date approach to the modelling of material non-linearity of concrete is based on using stress-strain diagrams modified for long-term effects. This approach enables to evaluate stress and strain state of reinforced concrete elements under any level of longterm loading [19].

The solution of the problem is mostly proposed to be found on the basis of the finite element method which enables taking into account material and geometric nonlinearity [20-22]. Normally, the non-linear physical relations are solved numerically using an incremental stepby-step Newton-type procedure. However, coordination of loading steps with time step increments, which is dictated by the Volterra's equation in order to simulate the concrete creep, is very time consuming and often requires computer parallelisation [23]. Therefore, engineers do not use the non-linear analysis methods in usual design practice. Furthermore, in general case, the problem of analysis of reinforced concrete elements under both short- and long-term loadings is non-smooth and non-convex and has multiple solutions, i e several stress and strain states may correspond to the same load condition [24]. This can be even if stress-strain relationships used for concrete and reinforcing steel have no descending branches. Therefore, conventional iterative methods of the Newton's type are frequently inefficient when solving a set of nonlinear equations for reinforced concrete structures and do not enable to find all possible solutions of the problems.

Deformational analysis of reinforced concrete columns subjected to long-term loads. The method is developed on the basis of the fracture and creep theories for concrete and using non-linear stress-strain diagrams modified for time effects. Second-order geometrical effects are taken into account. The technique proposed is verified by an extensive comparison of analysis results with experimental data.

\section{Physical relationships for reinforced concrete elements under long-term loading}

\subsection{Physical model}

Consider a beam/column reinforced concrete element under long-term unsymmetrical bending and tension/compression. Let us assume that shear forces and torsion do not significantly affect stress state and stiff-ness of the element cross-sections and can be omitted in non-linear formulations. In this case, stress and strain state at a crosssection of the element (Fig 1) can be evaluated by the following system of three non-linear equations:

$$
\begin{array}{ccc}
{\left[\begin{array}{ccc}
\varpi\left(t, t_{0}\right) & 0 & 0 \\
0 & B_{y}\left(t, t_{0}\right) & B_{y z}\left(t, t_{0}\right) \\
0 & B_{y z}\left(t, t_{0}\right) & B_{z}\left(t, t_{0}\right)
\end{array}\right] \times\left[\begin{array}{c}
\varepsilon_{o}\left(t, t_{0}\right) \\
\psi_{y}\left(t, t_{0}\right) \\
\psi_{z}\left(t, t_{0}\right)
\end{array}\right]=\left[\begin{array}{c}
N \\
M_{y} \\
M_{z}
\end{array}\right]} \\
\text { or } \\
{\left[B\left(\varepsilon\left(t, t_{0}\right)\right)\right] \times \mathbf{\varepsilon}\left(t, t_{0}\right)=\mathbf{S},}
\end{array}
$$

where $t$ is the time being considered; $t_{0}$ is the time at initial loading; $\left[B\left(\varepsilon\left(t, t_{0}\right)\right)\right]$ is the stiffness matrix for the cross-section, its elements are interdependent and given by:

$$
\begin{gathered}
\sigma\left(t, t_{0}\right)=\int_{A} \frac{\sigma(t)}{\varepsilon\left(t, t_{0}\right)} d A \\
B_{y}\left(t, t_{0}\right)=\int_{A} \frac{\sigma(t)}{\varepsilon\left(t, t_{0}\right)}\left(z-z_{o}\left(t, t_{0}\right)\right)^{2} d A ; \\
B_{z}\left(t, t_{0}\right)=\int_{A} \frac{\sigma(t)}{\varepsilon\left(t, t_{0}\right)}\left(y-y_{o}\left(t, t_{0}\right)\right)^{2} d A ; \\
B_{y z}\left(t, t_{0}\right)=\int_{A} \frac{\sigma(t)}{\varepsilon\left(t, t_{0}\right)}\left(y-y_{o}\left(t, t_{0}\right)\right)\left(z-z_{o}\left(t, t_{0}\right)\right) d A
\end{gathered}
$$

$\boldsymbol{\varepsilon}\left(t, t_{0}\right)=\left(\varepsilon_{o}\left(t, t_{0}\right) \psi_{y}\left(t, t_{0}\right) \psi_{z}\left(t, t_{0}\right)\right)^{T}$ is unknown strain vector including the current values of axial strain $\varepsilon_{o}\left(t, t_{0}\right)$ (at the stiffness centre $O$, Fig 1) and the curvatures $\psi_{y}\left(t, t_{0}\right), \quad \psi_{z}\left(t, t_{0}\right)$ about appropriate axes; 
$\mathbf{S}=\left(\begin{array}{lll}N & M_{y} & M_{z}\end{array}\right)^{T}$ is the vector of internal forces

(Fig 1); $\sigma(t)=\left(\sigma_{b}(t) \cap \sigma_{s}(t)\right)$ are the normal stresses acting in the direction of $X$ axis at time $t ; Y, Z$ are any orthogonal axes; $A \supseteq A_{b} \cup A_{s}$ is the cross-sectional area; subscripts $b$ and $s$ refer to concrete and reinforcing steel respectively.

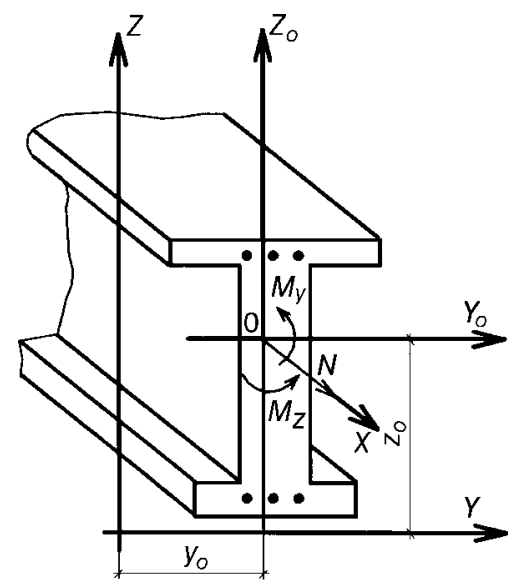

Fig 1. Cross-section and internal forces

Coordinates of the point $O$ at time $t$ are determined by the following expressions:

$$
\begin{aligned}
& y_{o}\left(t, t_{0}\right)=\frac{\int_{A} \frac{\sigma(t)}{\varepsilon\left(t, t_{0}\right)} y d A}{\int_{A} \frac{\sigma(t)}{\varepsilon\left(t, t_{0}\right)} d A} ; \\
& z_{o}\left(t, t_{0}\right)=\frac{\int_{A} \frac{\sigma(t)}{\varepsilon\left(t, t_{0}\right)} z d A}{\int_{A} \frac{\sigma(t)}{\varepsilon\left(t, t_{0}\right)} d A} .
\end{aligned}
$$

Assuming that sections remain plane, the strain $\boldsymbol{\varepsilon}\left(t, t_{0}\right)$ at a point with coordinates $(y, z)$ is obtained by:

$$
\begin{aligned}
\varepsilon\left(t, t_{0}\right)= & \varepsilon_{o}\left(t, t_{0}\right)-\psi_{y}\left(t, t_{0}\right)\left(z-z_{o}\left(t, t_{0}\right)\right)- \\
& \psi_{z}\left(t, t_{0}\right)\left(y-y_{o}\left(t, t_{0}\right)\right) .
\end{aligned}
$$

Normal stresses are calculated using arbitrary stressstrain relations for concrete and reinforcing steel (section 2.2). Note that effects of shear forces and torsion may be taken into account by using stress-strain relationship for concrete modified for these effects.

To compute the integrals presented in above expressions, the Gauss' and Simpson's quadrature formulae are used. This enables avoiding conventional division of the cross-sectional area into many elementary areas [20, 21].

Assume that if at least one solution of the system (1) exists, the strength of the cross-section will be assured.

\subsection{Constitutive laws for materials}

Stress-strain relations for concrete in uniaxial compression have been proposed by many researchers. However, most of the relations deal with a short-term loading and do not address changes in concrete properties during the loading process. Our proposal to modify constitutive relationship for concrete taking into account long-term effects is presented below.

For the modification of the stress-strain relationship for concrete under long-term loading let us consider only a "strict" loading regime when the load is applied for a short time not exceeding $1 \mathrm{~h}$ and maintained constant for a time $t-t_{0}$. In this case, the behaviour of compressed concrete we can model through modification [19, 25] of the relation given in prEN 1992-1 [26]:

$$
\begin{aligned}
& \sigma_{b}\left(\varepsilon_{b}\left(t, t_{0}\right)\right)= \\
& \frac{\frac{\varepsilon_{b}\left(t, t_{0}\right)}{v_{b R}\left(t, t_{0}\right) \varepsilon_{b R}\left(t, t_{0}\right)}-\left(\frac{\varepsilon_{b}\left(t, t_{0}\right)}{\varepsilon_{b R}\left(t, t_{0}\right)}\right)^{2}}{1+\left(\frac{1}{v_{b R}\left(t, t_{0}\right)}-2\right) \frac{\varepsilon_{b}\left(t, t_{0}\right)}{\varepsilon_{b R}\left(t, t_{0}\right)}} \gamma_{b 2}\left(t, t_{0}\right) R_{b}\left(t_{0}\right),
\end{aligned}
$$

where $\varepsilon_{b}\left(t, t_{0}\right)$ is the current concrete strain at time $t$; $\varepsilon_{b R}\left(t, t_{0}\right)$ is the peak concrete strain corresponding to the stress $\sigma_{b}(t)=R_{b}\left(t, t_{0}\right) ; v_{b R}\left(t, t_{0}\right)$ is the limit coefficient of elasticity at time $t ; R_{b}\left(t_{0}\right)$ and $R_{b}\left(t, t_{0}\right)$ are the short-term and long-term compressive strengths of concrete respectively; $\gamma_{b 2}\left(t, t_{0}\right)=\frac{R_{b}\left(t, t_{0}\right)}{R_{b}\left(t_{0}\right)}$ is the function of concrete long-term compressive strength.

The peak strain and the coefficient of elasticity of concrete are computed on the basis of the creep theory and investigations [25] as follows:

$$
\begin{gathered}
\varepsilon_{b R}\left(t, t_{0}\right)=\frac{R_{b}\left(t, t_{0}\right)}{v_{b R}\left(t_{0}\right) E_{b}\left(t_{0}\right)}\left(1+v_{b R}\left(t_{0}\right) f_{c} \varphi^{*}\left(t, t_{0}\right)\right) ; \\
1 / v_{b R}\left(t, t_{0}\right)=\gamma_{b 2}\left(t, t_{0}\right)\left(1+v_{b R}\left(t_{0}\right) f_{c} \varphi^{*}\left(t, t_{0}\right)\right),
\end{gathered}
$$

where $E_{b}\left(t_{0}\right)$ is the modulus of elasticity at time $t_{0} ; f_{c}$ is the factor, taking account of non-linear creep deformations; $v_{b R}\left(t_{0}\right)$ is the limit coefficient of elasticity at time $t_{0} ; \varphi^{*}\left(t, t_{0}\right)$ is the specific creep coefficient.

The specific creep coefficient is established taking into account changes of elastic deformations in time, as follows:

$$
\varphi^{*}\left(t, t_{0}\right)=\varphi\left(t, t_{0}\right)-\frac{E_{b}\left(t_{0}\right)}{E_{b}(t)}+1,
$$

where $E_{b}(t)$ is the modulus of elasticity at time $t$. by

The limit coefficient of elasticity at time $t_{0}$ is given

$$
v_{b R}\left(t_{0}\right)=\frac{R_{b}\left(t_{0}\right)}{E_{b}\left(t_{0}\right) \varepsilon_{b R}\left(t_{0}\right)}
$$


where $\varepsilon_{b R}\left(t_{0}\right)$ is the peak concrete strain when the corresponding stress is equal to $R_{b}\left(t_{0}\right)$.

Non-linear effects of concrete creep are taken into account using relations given in Recommendations [28]:

$$
f_{c}=1+v_{c}\left(\eta\left(t, t_{0}\right)\right)^{4},
$$

where $v_{c}$ is the factor, taking account of non-linear properties of concrete according to Recommendations [28] and our proposals regarding to accumulation of the stress history; $\eta\left(t, t_{0}\right)=\eta\left(t_{0}\right) \gamma_{b 2}\left(t, t_{0}\right)$ is the intensity of longterm loading; $\eta\left(t_{0}\right)$ is the intensity of short-term loading.

Compressed concrete fails due to crack formation and prolongation caused by tensile stresses in the orthogonal direction. The fracture energies $G_{f}\left(t_{0}\right)$, $G_{f}\left(t, t_{0}\right)$ and fracture process zone lengths $l_{p}\left(t_{0}\right)$, $l_{p}\left(t, t_{0}\right)$ describe the failure of concrete integrally.

In [29], it was found that $l_{p}\left(t_{0}\right) \approx l_{p}\left(t, t_{0}\right)$. Using the fracture theory, the function of the long-term compressive strength of concrete is evaluated through solving the following sixth-order equation [25]:

$\gamma_{b 2}\left(t, t_{0}\right)=$

$$
\sqrt{\frac{f_{g}(t) \beta_{c c}^{*}(t)^{2}}{1+v_{b R}\left(t_{0}\right) \varphi^{*}\left(t, t_{0}\right)\left(1+v_{c}\left(\theta\left(t, t_{0}\right)-\omega\left(t, t_{0}\right)\right)^{2} \beta_{c c}^{*}(t)^{4}\right)}},
$$

where:

$$
\begin{gathered}
\theta\left(t, t_{0}\right)=\frac{\sqrt[3]{\lambda\left(t, t_{0}\right)\left(v_{c} v_{b R}\left(t_{0}\right) \varphi^{*}\left(t, t_{0}\right)\right)^{2}}}{6 v_{c} v_{b R}\left(t_{0}\right) \varphi^{*}\left(t, t_{0}\right) \beta_{c c}^{*}(t)^{2}}, \\
\omega\left(t, t_{0}\right)=\frac{2\left(1+v_{b R}\left(t_{0}\right) \varphi^{*}\left(t, t_{0}\right)\right)}{\sqrt[3]{\lambda\left(t, t_{0}\right)\left(v_{c} v_{b R}\left(t_{0}\right) \varphi^{*}\left(t, t_{0}\right)\right)^{2}} \beta_{c c}^{*}(t)^{2}}, \\
\vartheta\left(t, t_{0}\right)=v_{b R}\left(t_{0}\right) \varphi^{*}\left(t, t_{0}\right)\left(12+27 v_{c} f_{g}(t)^{2} \beta_{c c}^{*}(t)^{4}\right),(19) \\
\lambda\left(t, t_{0}\right)=108 f_{g}(t) \beta_{c c}^{*}(t)^{2}+ \\
21 \sqrt{\frac{4+\vartheta\left(t, t_{0}\right)+4\left(v_{b R}\left(t_{0}\right) \varphi^{*}\left(t, t_{0}\right)\right)^{2}\left(3+v_{b R}\left(t_{0}\right) \varphi^{*}\left(t, t_{0}\right)\right)}{v_{c} v_{b R}\left(t_{0}\right) \varphi^{*}\left(t, t_{0}\right)}} .
\end{gathered}
$$

$\beta_{c c}^{*}(t)$ - coefficient taken into account the hydration of cement paste given in [25].

In [25], relationship (16) was compared with experimental data. The statistical analysis showed a good correspondence between the analysis and test results for concretes of various strengths.

Reinforcing steel at normal temperatures is not subject to any creep effects. Therefore the same stress-strain relation that may be defined by an arbitrary function can model both long-term and short-term steel behaviour.

\section{Static analysis}

Static analysis of reinforced concrete columns under long-term loading should take into account both physical and geometrical non-linear effects and be able to predict the real buckling behaviour. In general case of geometry and loading, the analysis can be performed incrementally using the finite element method. In every step of the analysis, the stiffness of the finite elements is recomputed using the formulae presented in section 2 that provide relationships between the vector of internal forces and the stiffness matrix of each element.

In a two-dimensional case, solution of the problem can be also found by using the approach that takes into account only second-order geometrical effects [27].

Consider a reinforced concrete line element under simple bending combined with compression (Fig 2).

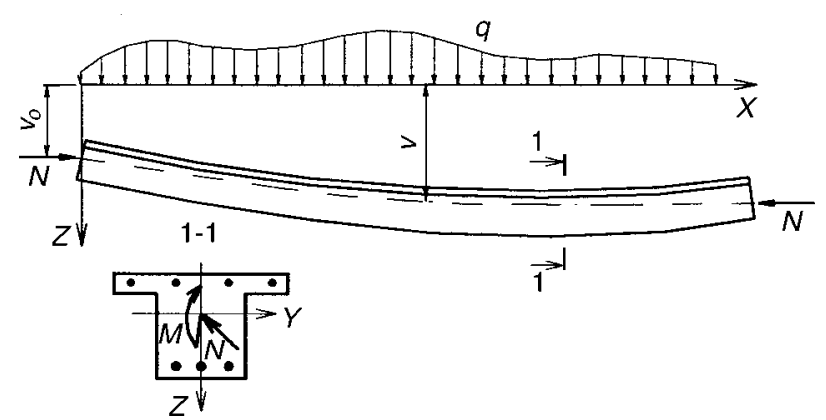

Fig 2. RC element under simple bending and compression

Differential equation for such elements is as follows:

$$
\psi \approx \frac{d^{2} v}{d x^{2}}=-M / B
$$

where $\psi$ is the curvature of the element longitudinal axis; exact expression for the curvature is substituted here for an approximate one taking into account only second-order geometrical effects:

$$
M=M_{q}+M_{N}=M_{q}+N\left(v-v_{0}\right) ;
$$

$M_{q}$ is the bending moment produced by the lateral loading only; $M_{N}$ is the bending moment produced by the compressive axial force $N$, computed relatively to the stiffness centre of the considered section (position of the stiffness centre varies along the element length forming a curved physical axis); $v$ and $v_{0}$ are the vertical displacements at sections with coordinates $x$ and 0 respectively; $B$ is the bending stiffness computed by solving the system of non-linear equations (1).

Referring to Eq (22), Eq (21) can be rewritten as follows:

$$
\frac{d^{2} v}{d x^{2}}+\frac{N}{B} v=-\frac{M_{q}}{B}+\frac{N}{B} v_{0}
$$




$$
\frac{d^{2} v}{d x^{2}}+k^{2} v=-k^{2} \frac{M_{q}}{N}+k^{2} v_{0}
$$

where $k^{2}=N / B$.

This linear inhomogeneous second-order differential equation with variable multipliers can be solved for given boundary conditions by numerical methods using special computer programmes. Note that in this case it is possible to use exact equation for the element axis curvature instead of approximate equation (21).

In order to find a solution of Eq (24), we substitute variable stiffness $B(x)$ for piecewise stiffness that is uniform along $i$-th segments of the lengths $a_{i}, \quad i \in 1: n$; the number of segments $n$ may be sufficiently large to attain the accuracy required.

The load applied to the element resulted in concentrated lateral $F_{i}$ and axial $P_{i}$ loads and moments $L_{i}$ applied to the edges of $i$-th segments and in uniformly distributed load $q_{i}$ on $i$-th segments (the load $q_{i}$ is applied along the entire length of $i$-th segment). In addition, on the edges of $i$-th segments the skips of rotation $\Delta \varphi_{i}$ and translation $\Delta v_{i}$ displacements are possible (Fig 3). The skips of displacements enable to model position of the element physical axis that changes during the loading.

After introduction of a dimensionless variable $\xi=k x$ and taking into consideration that $\frac{d^{n}}{d x^{n}}=k^{n} \frac{d^{n}}{d \xi^{n}}$, Eq is rewritten in the following form:

$$
\frac{d^{2} v}{d \xi^{2}}+v=-\frac{M_{q}}{N}+v_{0}
$$

Solution of Eq (25) can be written as a recurrence expression for lateral displacement on the edge of $i$-th segment, as follows:

$$
\begin{gathered}
v_{i}\left(\xi_{i}\right)=(v+\Delta v)_{i-1}+(\varphi+\Delta \varphi)_{i-1}\left(\frac{\sin \xi}{k}\right)_{i}- \\
-(M+L+N \Delta v)_{i-1}\left(\frac{1-\cos \xi}{N}\right)_{i}- \\
-(Q-F)_{i-1}\left(\frac{\xi-\sin \xi}{k N}\right)_{i}-q_{i}\left(\frac{1-\cos \xi-\frac{\xi^{2}}{2}}{k^{2} N}\right)_{i}
\end{gathered}
$$

where $\xi_{i}=k_{i} x_{i} ; \quad k_{i}^{2}=\frac{N_{i}}{B_{i}} ; \quad N_{i}=(N+P)_{i-1} ; \Delta v_{0}=0$, $\Delta \varphi_{0}=0 ; v_{0}, \varphi_{0}, M_{0}, Q_{0}$ are initial parameters.

Initial parameters and skips are computed from the given support conditions as well as from conditions on the segment boundaries.

Rotations ji, bending moments $M_{i}$ and shear forces $Q_{i}$ are expressed in terms of lateral displacements $v_{i}$

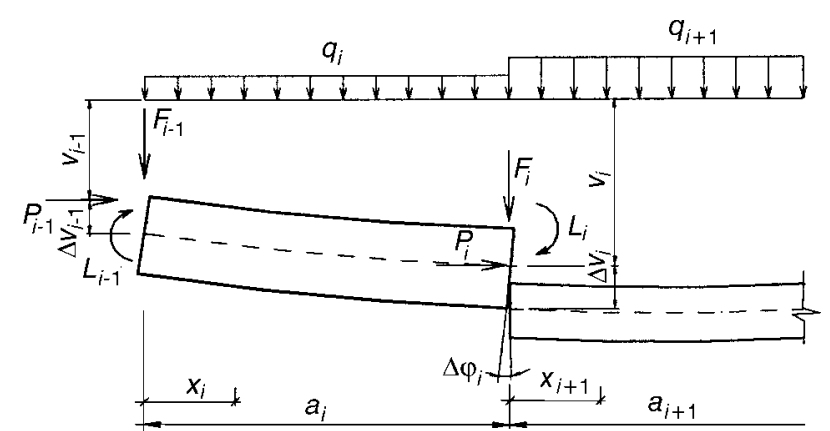

Fig 3. Elementary segments of the element: boundary conditions, loads and displacements

by the known differential relationships as follows:

$\varphi_{i}\left(x_{i}\right)=\frac{d v_{i}}{d x_{i}}, M_{i}\left(x_{i}\right)=-B_{i} \frac{d^{2} v_{i}}{d x_{i}^{2}}, Q_{i}\left(x_{i}\right)=\frac{d M_{i}}{d x_{i}}$.

So, using Eq (26) it is possible to analyse any line elements. Analysis of reinforced concrete columns under long-term loading is reduced to solving equation (26) subject to non-linear physical relationships (1). This analysis is iterative, the values of the bending stiffness $B$ are iterated for all segments into which the column has been divided.

In such a way, it is also possible to analyse elements under biaxial bending where principal axes of segments have different angles of inclination, ie deformations happen in different planes. Hence, computation of displacement and force components has to be performed separately for every segment, with a sequential transition from the global to local axes and back by known geometrical formulae.

\section{Numerical procedure}

Equation (26) subject to non-linear physical relations can be solved only iteratively. Research [24] showed that such problems are non-smooth and have multiplied solutions even if the stress-strain diagrams have no descending branches, ie several stress and strain states may correspond to the same load condition depending on the loading history. In such cases, conventional iterative Newton-type methods used for solving systems of nonlinear equations can frequently be unsuccessful and do not enable to find all solutions of the problem.

The governing relations for a $n$-times indeterminate reinforced concrete structure are given by a system of $n$ non-linear equations, ie:

$$
f(\mathbf{q}, \mathbf{S})=0
$$

or are represented by an optimization problem as follows:

$$
f_{0}(\mathbf{q}, \mathbf{S}) \rightarrow \min .
$$

They include a $n$-dimensional vector of unknown strains or displacements $\mathbf{q} \in \mathbf{R}^{n}$ and the corresponding 
given vector of forces or loads $\mathbf{S} \in \mathbf{R}^{n}$. These relations contain non-convex (non-monotonic) and non-smooth functions $f(\bullet) \in \mathbf{R}^{n}$ or $f_{0}(\bullet) \in \mathbf{R}^{n}$.

The methods for solving such problems should provide finding of all possible solutions. If the system has a potential, the global extremum should be searched among all local extrema of the extremal function $f_{0}(\bullet)$. In this study, two approaches are proposed for solving non-linear problems (27) and (28). Firstly, by using an ordered search algorithm as proposed by Alyavdin and Simbirkin [24] and, secondly, by using a genetic algorithm [30] for solving the problem of non-linear programming (28) that can present the problem (27) too. For example, the system of equations (2) may be rewritten in the forms of (27) and (28) respectively as follows:

$$
\begin{aligned}
f(\mathbf{q}, \mathbf{S})= & {\left[B\left(\varepsilon\left(t, t_{0}\right)\right)\right] \times \mathbf{\varepsilon}\left(t, t_{0}\right)-\mathbf{S}=0 ; } \\
& \sum_{i=1}^{3} f_{i}^{2}(\mathbf{q}, \mathbf{S}) \rightarrow \min .
\end{aligned}
$$

In solving optimization problem (30) by using a genetic algorithm, the vector of unknowns $\mathbf{q}$ is represented by a single "chromosome", ie a binary chain containing values of unknowns in the binary number system. The length of this chain is dependent on the number of unknowns $n$ and required accuracy. The algorithm deals simultaneously with a number of these chromosomes called "population". Search of a solution of the optimization problem (30) consists in creating the "fittest" chromosome (individual) through modelling the processes of Darwinian evolution - mating, mutation and natural selection [30].

In order to make a genetic algorithm more efficient, an implementation technique taking account of peculiarities of the considered problems is developed. This technique is based on the results of Batistchev and Isaev [31] and is as follows. Selection of chromosomes is performed by using a method of supplanting. The selection based on this method is of a bicriterion nature, ie an individual becomes a member of a new generation not only through analysing its fitness but also considering if there is an individual with the same chromosome set in the generated population. In this way, two purposes are achieved: the best solutions having different chromosome sets are not lost and a genetic diversity is always maintained in the population. Supplanting creates here a new population rather from dissimilar individuals than individuals close to the current best solution.

Choosing parents for reproduction is performed using also two opposite methods - in-breeding and outbreeding. In-breeding chooses the first individual of a couple at random and the second individual will be that the closest to the first one. On the contrary, out-breeding creates couples from the most dissimilar individuals. In-breeding makes the search concentrated at local areas of a search space that leads to partitioning of the space into separated local groups around the places suspected to be extremums. Out-breeding is aimed to the prevention of a fast convergence of the algorithm to already found solutions making the algorithm to scan new, unexplored areas.

The method and the algorithm described above are implemented in a computer programme written in Visual Basic programming language as a macro for MS Excel.

\section{Experimental verification of the method}

Experimental verification of the method proposed above we will perform through a comparison of analysis and test values of load-carrying capacity and lateral deflections of reinforced concrete columns. In the first case, it is interesting to obtain a verification of stress-strain relation (10) and equation (16) proposed for consideration of the long-term effects using theoretical assumptions regarding the concrete fracture. In the second case, we will examine an agreement between calculated and measured increase of lateral displacements at time. In such a way, the proposed models of reinforced concrete elements will be approved for full range of long-term loading.

The analysis carried out for the experimental verification is based on the following assumptions:

1. Behaviour of concrete in long-term compression is modelled by using modified stress-strain relation (10) taking into account relation (16);

2. Descending branch of the stress-strain relationship for concrete is defined by function (10) where the concrete ultimate strain and the corresponding stress are approximately assumed to be $\varepsilon_{b u}\left(t, t_{0}\right) \approx 1,9 \varepsilon_{b R}\left(t, t_{0}\right)$ and $R_{b u}\left(t, t_{0}\right) \approx 0,85 R_{b}\left(t, t_{0}\right)$ respectively;

3 . Concrete tensile strength is ignored when determining the ultimate cross-section capacity;

4. No slip takes place between concrete and reinforcement;

5. For soft reinforcing steel, a diagram with yield plateau and non-linear strain hardening up to the peak stress equal to the ultimate strength is used, for reinforcing steel without yield plateau a non-linear branch of the diagram is defined by a quadratic function.

In experimental investigations performed by Drysdale et al [32], reinforced concrete columns were tested for long-term compression combined with simple bending. The columns of series D had an eccentricity of the axial force that accepted to be uniform along the column height and equal to $25.4 \mathrm{~mm}$. The cylinder concrete compressive strength was about $30 \mathrm{MPa}$. The tests showed that fracture of columns occurred 14 to 245 days after the load had been applied and the long-term capacity was 122 to $136 \mathrm{kN}$. The short-term ultimate load of the columns was approximately equal to $182 \mathrm{kN}$. The rest data are taken from [32]. Comparative graphs for calculated by using the proposed method, design code SNiP [4] and test [32] values of the ultimate load $P_{u}$ are shown in Fig 4. 


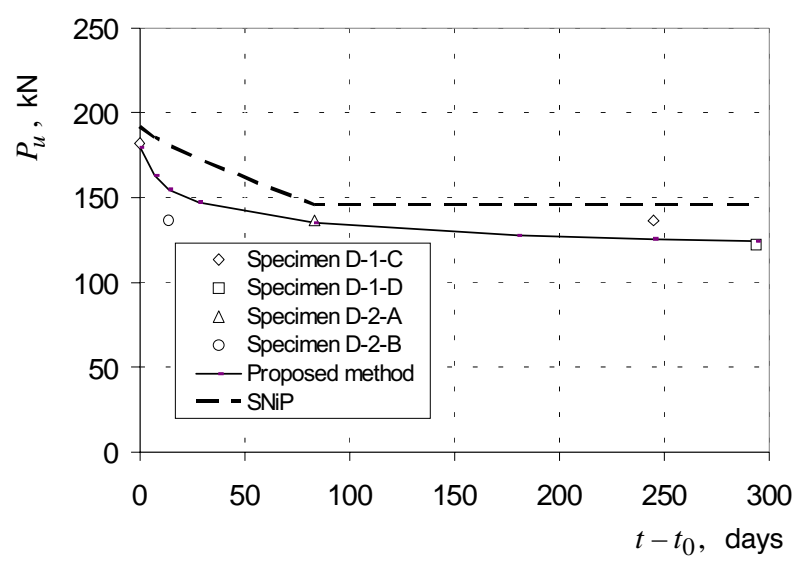

Fig 4. Calculated and experimental values of the ultimate failure load $P_{u}$ for RC columns

The results obtained by using the proposed method are in a good agreement with the experimental values of the load-carrying capacities. When using the code SNiP [4] the ultimate short-term and long-term loads were computed only after predictor-corrector calculations. The short-term ultimate failure load of columns calculated by using the code [4] is $190 \mathrm{kN}$. The long-term ultimate load is $145 \mathrm{kN}$. The kind of the dashed line shown in Fig 4 cannot be obtained by calculations according to SNiP [4], since this code does not define the time-depending alteration of the unit creep characteristics, such as specific creep or creep coefficients.

Tests studying the structural behaviour of slender high-strength and normal-strength reinforced concrete columns subjected to sustained loading were carried out by Claeson et al $[33,34]$. The columns had a quadratic cross-section of $200 \times 200 \mathrm{~mm}$ and were $4 \mathrm{~m}$ high. Concrete compressive strengths were $35 \mathrm{MPa}$ (column N201) and $92 \mathrm{MPa}$ (column H201), load eccentricity was equal to $20 \mathrm{~mm}$. The rest data are taken from [32].

Fig 5 presents diagrams comparing theoretical and experimental [33] values of long-term lateral deflections of the high-strength concrete column H201. As can be seen, the deflections calculated by using the method proposed are very close to the measured ones. It is also

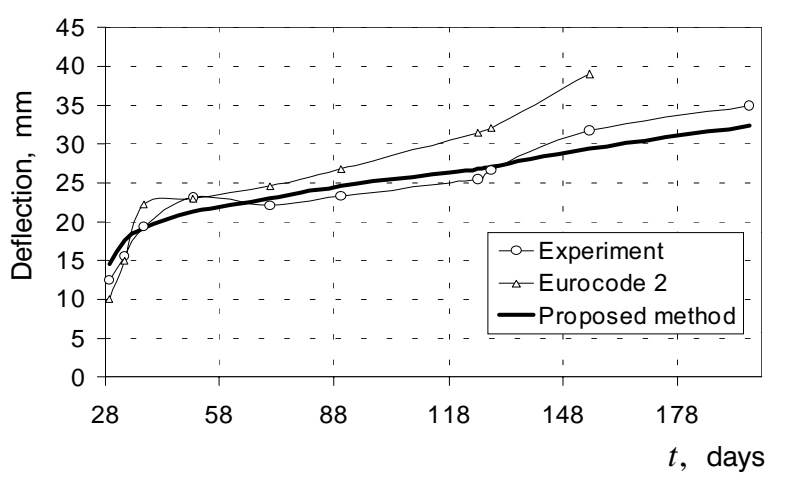

Fig 5. Long-term measured and calculated maximum lateral deflections of high-strength $\mathrm{RC}$ column seen that Eurocode 2 [26] overestimates the creep deformations of the high-strength concrete.

In experimental investigations [33], after six months of unvaried loading it was decided to finish the sustained loading and subject the column to an increasing shortterm load up to the failure to determine the residual strength. The column had not been unloaded before the increasing load was applied. The total ultimate failure load was equal to $1367 \mathrm{kN}$, and the maximum lateral deflection to $57 \mathrm{~mm}$. Theoretically, using the proposed method we obtained almost the same values: the column starts to buckle under the load of $1365 \mathrm{kN}$ at the maximum deflection equal to $58 \mathrm{~mm}$.

Goyal et al [35] described experimental results of pin-ended eccentrically loaded columns subjected to sustained load for a period of 6 months and then to an increasing load under short-term loading conditions up to the failure. The columns had a cross-section of $76 \times 76$ $\mathrm{mm}$ and were $1828 \mathrm{~mm}$ (series A and I), $1219 \mathrm{~mm}$ (series P) high. Concrete cylinder compressive strengths were ranging between 26 and $33 \mathrm{MPa}$, and the load eccentricities were 13 to $38 \mathrm{~mm}$. The rest data are taken from [35].

Fig 6 presents axial compressive load versus lateral deflection diagrams obtained for full loading history by experiments [35] and theoretically by using the method proposed. As can be seen, deflections calculated by using the proposed technique are close enough to the measured ones.

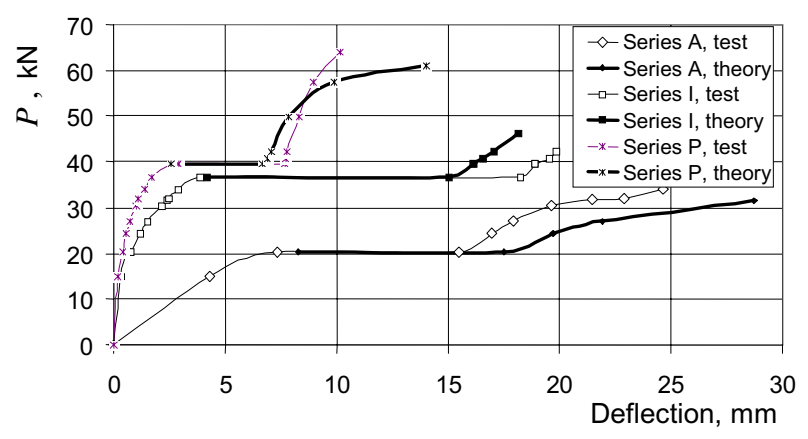

Fig 6. Long-term experimental and calculated lateral deflections vs compressive load diagrams

Mickleborough et al [36] measured long-term deflections of reinforced concrete columns which had concrete strength ranging between 27 and $39 \mathrm{MPa}$. The results presented in [36] cover duration of experiments of 40 days. Test types $\mathrm{A}, \mathrm{B}$, and $\mathrm{C}$ involved columns with a cross-section of 150x150 mm and a span length $6 \mathrm{~m}$. Eccentricities of the compressive load were ranging between 15 and $60 \mathrm{~mm}$. The rest data are taken from [36].

Fig 7 presents curves comparing theoretical and experimental [36] values of lateral deflections of reinforced concrete columns under long-term loading. As can be seen, the deflections calculated by using the method proposed are also close enough to the measured ones. 


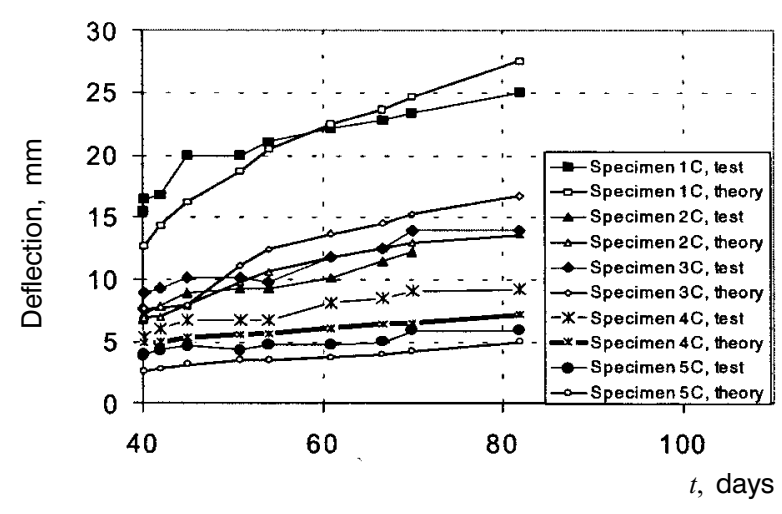

Fig 7. Long-term experimental and calculated lateral deflections of RC columns

An agreement between the calculated and measured values of long-term lateral deflections of RC columns has been also estimated statistically (Fig 8).

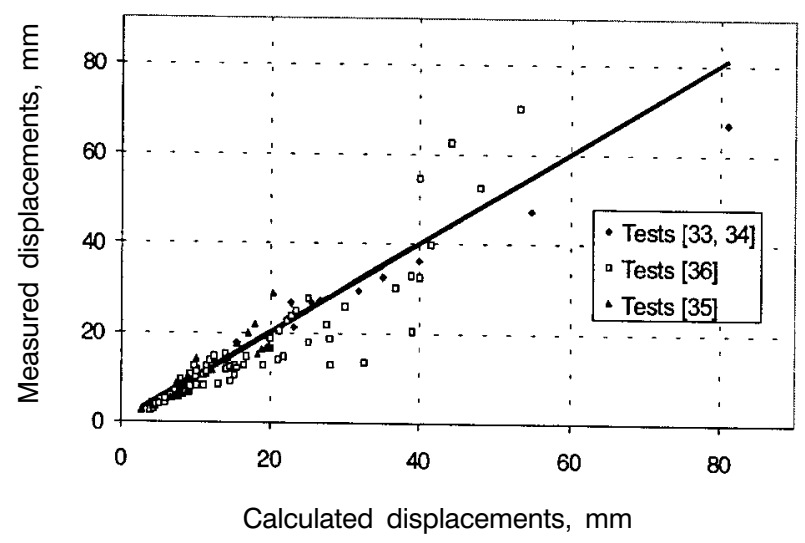

Fig 8. Adequacy of long-term experimental and calculated lateral displacements of RC columns

The ratios $\kappa=v_{c a l} / v_{\text {exp }}$ are calculated for all time moments for which the authors of the experimental research [33-36] have presented the test results, standard deviations and coefficient of variation are also computed. The statistical analysis deals with the sample of 116 points obtained for 22 test specimens. It has been found that long-term deflections calculated by the method proposed differ from the experimental values on average by $8 \%$ with variation coefficient of $21 \%$. This may be treated as a rather good agreement between analysis and test results.

Here we can notice that a great part of the considered slender columns buckled immediately after formation of a crack. Therefore, the load-carrying capacity of such columns is determined by the cracking moment and, hence, strongly depends on the concrete tensile strength. However, the latter value is frequently hardly controlled and even indeterminate, especially under long-term loading conditions. This fact partly explains the differences between calculated and experimental results.

\section{Conclusions and recommendations}

The results obtained in the present study may be generally summarised as follows:

1. Non-linear response of reinforced concrete columns to long-term loads can be modelled on the basis of the concrete creep and fracture theories using concrete stress-strain relations modified for long-term effects. The method proposed in this paper enables to take into account second-order geometric effects, as well as nonlinear material properties, cracking, and both linear and non-linear creep effects and to predict strength and deformations of reinforced concrete elements throughout the loading process up to failure.

2. A computation technique based on a genetic algorithm provides avoiding difficulties associated with non-smoothness, non-convexity and presence of multiple solutions of the system of equations modelling non-linear response of reinforced concrete elements to long-term loads.

3. The method proposed is found to be of an adequate accuracy by a statistical analysis of calculated and experimental data and can be used for analysis of reinforced concrete columns subjected to long-term loads.

4. The difficulties of analysis and the differences between test and analysis results for slender reinforced columns under long-term loading may be caused by a hard control and rough prediction of the concrete tensile strength that has a great influence on the load-carrying capacity of the columns failed immediately after the crack formation.

\section{References}

1. Quast, U. Dimensioning of Slender Elements Related to Ultimate Limit States by Structural Deformations - Stability check. Concrete Structures. Euro-Design Handbook. 1994/1996. Berlin: Ernst \& Sohn, 1995, p. 453-513.

2. Real, M. de V.; Filho, A. C.; Maestrini, S. R. Response variability in reinforced concrete structures with uncertain geometrical and material properties. Nuclear Engineering and Design, 2003 (in press).

3. Diniz, M. C.; Frangopol, D. M. Safety evaluation of slender high-strength concrete columns under sustained loads. Computers and Structures, 81, 2003, p. 1475-1486.

4. SNiP 2.03.01-84* . Concrete and Reinforced Concrete Structures. Design Code. (СНиП 2.03.01-84*. Бетонные и железобетонные конструкции. Нормы проектирования). Moscow: Gosstroi SSSR, 1989. 80 p. (in Russian).

5. ACI Committee 318. Building Code Requirements for Reinforced concrete (ACI 318-95/ACI 318R-95) ACI Manual of Concrete Practice. Detroit: American concrete institute, 1996. $300 \mathrm{p}$.

6. Rangan, B. V. Strength of Reinforced Concrete Slender Columns. ACI Structural Journal, Vol 87, No 1, 1990, p. 32-38. 
7. Bazant, Z. P.; Cedolin, L.; Tabbara, M. R. New Method of Analysis for Slender Columns. ACI Structural Journal, Vol 88, No 4, 1991, p. 391-401.

8. Bradford, M. A. Service Load Analysis of Slender R-C Columns. ACI Structural Journal, Vol 94, No 6, 1997, p. 675-685.

9. Sheikh, S. A.; Yeh, C. C. Analytical Moment-Curvature Relations for Tied Concrete Columns. Journal of Structural Engineering, Vol 118, No 2, 1992, p. 529-544.

10. Manzelli, A. A.; Harik, I. E. Approximate Moment-Curvature Relationships for Slender Column. Journal of Structural Engineering, Vol 119, No 4, 1993, p. 1114-1132.

11. Rodriguez-Gutierrez, J. A.; Aristizabal-Ochoa, J. D. $M-P-F$ Diagrams for Reinforced, Partially and Fully Prestressed Concrete Sections under Biaxial Bending and Axial Load. Journal of Structural Engineering, Vol 127, No 7, 2001, p. 763-773.

12. Hsu, T. T. C. Towards a Unified Nomenclature for Reinforced Concrete Theory. Journal of Structural Engineering, Vol 122, No 3, 1996, p. 275-283.

13. Bazant, Z. P.; Cedolin, L. Stability of Structures. Elastic, Inelastic, and Damage Theories. New York: Oxford University Press, 1991. 984 p.

14. Cypinas, I. Rèminių konstrukcijų neteisinè ittaka. Liaunumo itaka. Netiesinè betono elgsena. Valkšnumas (Non-linear Analysis of Frame Structures. Buckling Influence. Nonlinear Behaviour of Concrete. Creep) Kaunas: Tecnologija, 1997. 195 p. (in Lithuanian).

15. Diener, J. Contribution to physically and geometrically nonlinear analysis of reinforced concrete and prestressed concrete structural members subjected to long-term loads taking into account non-linear creep effect and cracking (Beitrag zur physikalisch und geometrisch nichtlinearen Berechnung langzeitbelasteter Bauteile aus Stahlbeton und Spannbeton unter besonderer Berücksichtingung des nichtlinearen Kriechens und der Rißbildung). PhD thesis, Bauhaus-Universität. Weimar: 1998. 202 p. (in German).

16. Bondarenko, V. M.; Bondarenko, S. V. Engineering Methods of Non-linear Theory of Reinforced Concrete (Инженерные методы нелинейной теории железобетона). Moscow: Strojizdat, 1982. 287 p. (in Russian).

17. Mazzotti, C.; Savoia, M. An Incremental Non Linear Creep Damage Model for Concrete in Compression. CD-ROM Proc. of the European Conf. on Computational Mechanics ECMM-2001, June 26-29, 2001, Cracow, Poland.

18. Barpi, F.; Valente, S. Creep and fracture in concrete: a fractional order rate approach. Engineering Fracture Mechanics, 70, 2003, p. 611-623.

19. Balevičius, R.; Simbirkin, V. Modeling of Physical NonLinearity of Reinforced Concrete Elements under LongTerm Loading. Mechanika, No 4(42). Kaunas: Technologija, 2003, p. 19-26.

20. Cypinas, I. Non-linear Deformation and Stability of Reinforced Concrete Column under the Long-time Load. Civil Engineering (Statyba), Vol 5, No 3. Vilnius: Technika, 1999, p. 176-182.

21. Kim, J. K.; Yang, J. K. Buckling behaviour of slender highstrength concrete columns. Engineering Structures, Vol 17, No 1,1995 , p. $39-51$.
22. Wu, Y.; Luna, R. Numerical implementation of temperature and creep in mass concrete. Finite Elements in Analysis and Design, No 37, 2001, p. 97-106.

23. Romero, M. L.; Miguel, P. F.; Cano, J. J. A Parallel Procedure for Nonlinear Analysis of Reinforced Concrete Three-Dimensional Frames. Computers and Structures, 80, 2002, p. 1337-1350.

24. Alyavdin, P. V.; Simbirkin, V. N. Solution of non-smooth problems in analysis of reinforced concrete structures. Construction (Будаўніцтва. Строительство), № 1, 2001, p. 11-21 (in Russian).

25. Balevičius, R. Evaluation of Physical Non-linearity of Concrete under Compressive Long-term Loading. Journal of Civil Engineering and Management, Vol IX, Suppl 2. Vilnius: Technika, 2003, p. 113-121 (in Lithuanian).

26. prEN 1992-1 (Final draft). EuroCode 2: Design of Concrete Structures. European Committee for Standardization, October 2001. 230 p.

27. Aliawdin, P.; Simbirkin, V. Behaviour of reinforced concrete elements under restrained flexure. In: Problems in Construction (Problemy budownictwa). Zielona Góra: Uniwersytet Zielonogórski, 2003, p. 97-110.

28. Recommendations for the Estimation of Concrete Creep and Shrinkage in Analysis of Plain and Reinforced Concrete Structures (Рекомендации по учету ползучести и усадки бетона при расчете бетонных и железобетонных конструкций). Moscow: NIIZHB, Gostroi SSSR, 1988. 122 p. (in Russian).

29. Zaitsev, Yu. V. Application of fracture mechanics methods in modelling of deformation and strength of concrete (Моделирование деформаций и прочности бетона методами механики разрушения). Moscow: Strojizdat, 1982. 196 p. (in Russian).

30. Haupt, R. L.; Haupt, S. E. Practical Genetic Algorithms. New York: A Wiley-Interscience Publication, 1998. 177 p.

31. Batistchev, D. I.; Isaev, S. A. Optimization of Multiextremal Functions Using Genetic Algorithms. In: High technologies in engineering, medicine and education (Высокие технологии в технике, медицине и образовании. Межвузовский сб. научн. тр.). Voronezh: VGTU, 1997, p. 4-17 (in Russian).

32. Drysdale, R. G.; Huggins, M. W. Sustained Biaxial Load on Slender Concrete Columns. Journal of the Structural Division, May 1971, p. 1423-1441.

33. Claeson, C; Gyltoft, K. Slender Concrete Columns Subjected to Sustained and Short-Term Eccentric Loading. $A C I$ Structural Journal, Vol 97, No 1, 2000, p. 45-52.

34. Claeson, C; Gyltoft, K. Slender High-Strength Concrete Columns Subjected to Eccentric Loading. Journal of Structural Engineering, Vol 124, No 3, 1998, p. 233-239.

35. Goyal, B; Jackson, N. Slender Concrete Columns under Sustained Load. Journal of the Structural Division, November, 1971, p. 2729-2750.

36. Mickelborough, N. C; Gilbert, R. I. Creep Buckling of Uniaxially Loaded Reinforced Concrete Columns. Symposium on Computer Analysis of the Effects of Creep, Shrinkage and Temperature Changes on Concrete Structures. $A C I$ Special Publications-129, 1991, p. 39-54. 